\title{
Inflammation and Microcalcification: A Never-Ending Vicious Cycle in Atherosclerosis?
}

\author{
Lynn Kawtharany $^{a}$ Laurence Bessueille $^{a}$ Hawraa Issa $^{b}$ Eva Hamade $^{c}$ \\ Kazem Zibara ${ }^{c}$ David Magne ${ }^{a}$ \\ aCBMS UMR CNRS 5246, Université Claude Bernard Lyon 1, Lyon, France; ${ }^{b}$ College of Public Health, Phoenicia \\ University, Zahrani, Lebanon; CPRASE and Biology Department, Faculty of Sciences-I, Lebanese University, Beirut, \\ Lebanon
}

\section{Keywords}

Atherosclerosis · Inflammation · Calcification · Ossification · Cartilage

\begin{abstract}
Inflammatory cells and cytokines are known for long to worsen the development of atherosclerotic plaques in mice, and intense efforts are today devoted to develop antiinflammatory therapeutic strategies to slow down plaque development. Increasing data indicate that plaque inflammation is intimately associated with microcalcifications, which exert harmful effects eventually culminating with plaque rupture. In this review article, we will first introduce microcalcification location, detection, and effects in atherosclerotic plaques. Then, we will present the numerous data suggesting that inflammatory cells and molecules are responsible for the formation of microcalcifications and the articles showing that microcalcifications stimulate macrophages and smooth muscle cells to produce more pro-inflammatory cytokines. Finally, we will discuss the possibility that microcalcifications might stimulate smooth muscle cells to produce larger and more stable calcifications to stabilize plaques, to exit the vicious cycle associating inflammation and microcalcification in atherosclerotic plaques.

(c) 2022 S. Karger AG, Basel
\end{abstract}

\section{Atherosclerosis: A Chronic Inflammatory Disease}

Atherosclerosis is now recognized as a chronic inflammatory condition, not simply as a lipid storage disease, where cells from both innate and adaptive immunity are involved in its pathogenesis [1]. Instead, inflammation is involved in the majority of atherosclerosis stages, starting from the initial recruitment of circulating inflammatory cells, the formation and progression of plaques, to the eventual rupture of the latter, leading to thromboticrelated complications [2]. The initial stage of atherosclerosis is primarily mediated by the activation, dysfunction, and structural changes of endothelial cells. This activation can be potentially triggered by routine habits, such as smoking and high saturated-fat diet, as well as the presence of comorbidities such as hypertension, obesity, hyperglycemia, and insulin resistance. The initial phase of atherosclerosis is mediated by the subendothelial accumulation of lipid molecules, including low-density lipoprotein (LDL), which will undergo oxidation by free radicals such as reactive oxygen species (ROS) and oxidative enzymes like lipoxygenases. This would eventually stimulate the expression of various chemokines, for example, C-C motif ligand 2, and different adhesion molecules, including E-selectin and vascular cell adhesion 
molecule-1. The expression of these adhesion molecules, vascular cell adhesion molecule-1 in particular, leads to the adhesion of innate (monocytes, macrophages, and neutrophils) and adaptive (T lymphocytes) immune cells as well as activated thrombocytes to the endothelium. While interacting with other leukocytes, activated thrombocytes secrete more cytokines in order to further establish immune cell infiltration. For example, monocytes penetrate the tunica intima of the vascular wall through diapedesis, where they differentiate into macrophages or dendritic cells. In the same context, macrophages will engulf the modified lipoprotein molecules, leading to the accumulation of cholesterol esters, thus becoming foam cells.

On the other hand, vascular smooth muscle cells (VSMCs) have been shown to give rise to plaque macrophages and foam cells. Rong et al. [3] provided the first demonstration of the acquisition by mouse aortic VSMCs of macrophage-like features after they were cholesterol loaded in vitro. The authors demonstrated that these cholesterol-loaded VSMC foam cells not only had downregulation of contractile markers (ACTA2 and MYH11) but also possessed upregulation of key macrophage and phagocytosis marker genes (CD68 and Lgals3). Later on, ex vivo approaches using co-staining for cell-specific markers revealed the phenotype conversion of VSMCs of the human coronary artery to a macrophage-like state during human atherogenesis [4]. By quantifying VSMC foam cells in human coronary lesions, the authors showed that they contribute to up to $50 \%$ of total foam cells. Additional in vivo studies using the combination of single cell RNA sequencing and VSMC lineage tracing also showed that VSMCs can transdifferentiate, express proinflammatory cytokines, and perform phagocytosis $[5,6]$, and that the contribution of VSMCs within atherosclerotic plaques has been greatly underestimated since they contribute up to $80 \%$ of total foam cells in advanced atherosclerosis [7]. Overall, these data demonstrate the involvement of VSMCs in the lipid uptake and formation of foam cells. It is worth noting that in addition to VSMCs, intimal pericytes are also involved in lipid accumulation and the formation of foam cells (reviewed in [8]).

Macrophages multiply, releasing various growth factors, cytokines, and chemokines that occasionally mediate monocytic/T-cellular infiltration in addition to amplifying pro-inflammatory signals. Several pro-inflammatory cytokines, including interferon-gamma, interleukins (IL-1 $\alpha$, IL-1 $\beta$, IL-4, IL-6, IL-12, IL-15, and IL-18), and tumor necrosis factor (TNF), as well as various antiinflammatory cytokines, such as IL-10, and family members of transforming growth factor-beta (TGF- $\beta$ ), bone morphogenic proteins (BMPs), and growth differentiation factors, have been reported to be released by activated macrophages in atherosclerotic plaques [9]. Moreover, the progressive accumulation of cholesterol in macrophages leads to endoplasmic reticulum (ER) stress and apoptosis [10], while the compromised clearance of apoptotic debris triggers cell necrosis that will further amplify plaque inflammation [11]. Finally, inflammation is directly associated with the formation of a thinner fibrous cap through impeding the integrity of the interstitial collagen matrix, by inhibiting VSMCs to form new collagen fibers, or by promoting the destruction of already existing collagen fibers [12-14].

\section{Microcalcifications, but Not Large Calcifications, Are Harmful}

\section{Different Types of Calcifications in Human Plaques}

Vascular calcification can develop in several locations and conditions. Calcification associated with atherosclerosis is in general restricted to the intima, but patients with atherosclerosis and type 2 diabetes and/or chronic kidney disease also develop intense medial calcification (reviewed in [15]). If both intimal calcification associated with atherosclerosis and medial calcification associated with diabetes or kidney disease can occur in the same individuals, they occur in distinct tissues and probably have different origin and impact. Therefore, in order to try deliver an understanding message, we will focus this review on intimal plaque calcification. Calcification is a hallmark of atherosclerosis [16] and is believed to profoundly affect plaque stability, mainly because the coronary artery calcium (CAC) score predicts cardiovascular mortality [17]. However, the CAC score commonly measures the calcium content in a patient [18], but it does not give information on the size or type of calcifications that may cause plaque rupture. In fact, calcifications in human plaques are far from being uniform, rather each type of calcification is likely to exert a specific impact on plaque stability [19-21]. The earliest calcifications, also called microcalcifications, are characterized by a size less than $50 \mu \mathrm{m}$, mainly originating from the lipid pool and early necrotic core, but can also be formed in the fibrous cap [20-22]. The mechanisms presumably involved in their formation will be presented in the Inflammation Induces Microcalcification section. Generally, these microcalcifications progress to form larger calcifications, such as sheets of calcification where both collagen and necrotic core are 
calcified. Sheet calcifications may in turn fracture into nodular calcifications [20]. Finally, plaque ossification is predominantly observed in peripheral arteries $[19,20]$.

\section{Heavily Calcified Plaques Are Stable}

Nowadays, increasing data indicate that heavily calcified plaques, with sheets of calcification or ossification, are stable, in contrast to plaques with small and diffuse calcifications (reviewed in [20,21, 23, 24]). Indeed, intravascular ultrasound (IVUS) imaging showed that vulnerable plaques are characterized by the presence of spotty calcifications [25]. This was confirmed by optical coherence tomography (OCT) studies, which reported that plaque rupture correlates positively with the number of spotty calcifications, but negatively with the number of large calcium deposits [26, 27]. Although IVUS and OCT cannot give precise information on calcification size, these studies collectively suggested that small and diffuse calcifications are more dangerous than fewer and bigger ones (reviewed in [24]). This paradigm seems strengthened by a recent histological study of 687 symptomatic or asymptomatic human carotid plaques revealing that microcalcifications were predominantly observed in unstable plaques, whereas macrocalcifications were present in stable ones [28]. The paradigm that strongly calcified plaques are stable has been further bolstered by the effects of statins on plaque development. It is now well accepted that statins reduce adverse clinical cardiovascular events $[29,30]$, and relatively recent IVUS imaging studies revealed that statins decrease plaque surface but increase their calcification $[31,32]$, which was confirmed by computed tomography and magnetic resonance imaging [3337]. More recently, administration of pravastatin to apoplipoprotein (Apoe)-deficient mice for 10 weeks resulted in a coalescence of microcalcifications into bigger calcifications [38]. Contrary to the amount of lipids, the mechanical impact of macrocalcifications on plaque stability is probably more stabilizing than harmful [39].

\section{Microcalcifications Are Harmful}

Microcalcifications measuring less than $50 \mu \mathrm{m}$ and invisible with conventional imaging approaches were suggested to provoke plaque rupture by the Weinbaum's group 15 years ago. Using in vitro approaches, they proposed that microcalcifications originating in the necrotic core are not dangerous, since they are essentially floating debris; however, those that form in the fibrous cap are particularly harmful because they generate a mechanical stress on the cap [40]. In fact, nearly all fibrous caps contain microcalcifications smaller than $5 \mu \mathrm{m}$, but only those that will grow above $10 \mu \mathrm{m}$ may exert dangerous mechanical stress [22]. In addition, microcalcifications might not be dangerous only by exerting mechanical stress but also by triggering and/or amplifying plaque inflammation. Using ${ }^{18} \mathrm{~F}$-sodium fluoride PET/computed tomography, Joshi and colleagues [41] reported that microcalcifications were associated with macrophage infiltration and apoptosis in culprit plaques in carotid endarterectomy specimens from patients with symptomatic carotid disease. Moreover, the number of coronary microcalcifications was shown by OCT to be positively associated with the presence of macrophages [42]. Interestingly, as plaque calcification progresses, macrophage infiltration decreases and plaques become less symptomatic $[43,44]$. Understanding how microcalcifications form and evolve toward bigger but less dangerous calcifications and the relative contribution of VSMCs and macrophages is therefore crucial $[23,45]$.

\section{Inflammation Induces Microcalcification}

Experimental data in humans and animal models suggest that inflammation triggers microcalcification. For instance, a clinical study with ${ }^{18} \mathrm{~F}$-fluorodeoxyglucosePET conducted on 137 patients revealed that arterial inflammation precedes calcium deposition at the same location [46]. In addition, a very recent study using single photon emission computed tomography/CT imaging revealed that there was an inverse correlation between inflammation and calcification volume in highly calcified human plaques [47], supporting the notion that inflammation precedes calcification [46]. Similarly, in Apoe-deficient mice, dual near-infrared spectroscopy imaging of both macrophages and calcium also revealed that inflammation precedes calcification [48]. To date, several cellular and molecular mechanisms have been proposed to explain the mechanism by which inflammation triggers plaque calcification.

\section{Macrophages Themselves May Induce Calcification} Macrophages May Induce Calcification through Cell Apoptosis/Necrosis

It is well known that cell necrosis is a potent inducer of pathological calcification [49]. In fact, calcifying dead macrophages in the necrotic core are often where microcalcifications initiate in human coronary arteries [21]. Extracellular concentrations of calcium and inorganic phosphate $\left(\mathrm{P}_{\mathrm{i}}\right)$ are close to those that cause spontaneous precipitation in many biological fluids. Hence, calcification 
is constantly inhibited by the production of extracellular inhibitors, such as inorganic pyrophosphate $\left(\mathrm{PP}_{\mathrm{i}}\right)$ or matrix Gla protein (MGP). Genetic deficiency in MGP, or in ectonucleotide pyrophosphatase phosphodiesterase 1 , an enzyme generating $\mathrm{PP}_{\mathrm{i}}$ from extracellular adenosine triphosphate, results in spontaneous vascular calcification $[50,51]$. Inside living cells, calcium and phosphate ions are normally physically separated to prevent the precipitation of calcium phosphate crystals. While calcium is stored in the ER and mitochondria, inorganic phosphate $\left(\mathrm{P}_{\mathrm{i}}\right)$ is mainly located in the cytoplasm where calcium levels are very low [52]. This separation is normally preserved during apoptosis, during which apoptotic bodies that are phagocytosed by macrophages are not calcified. However, when apoptotic body clearance is delayed, apoptotic cells and bodies undergo secondary necrosis during which membranes can break allowing calcium and $P_{i}$ to interact and precipitate. It is well known that compromised macrophage phagocytosis of apoptotic bodies is a hallmark of atherosclerosis plaques [11], which might significantly contribute to the formation of early microcalcifications [21]. Finally, not only the release of $P_{i}$ but also organic phosphates might also participate in initiation of plaque calcification [53]. The release of DNA in particular could be involved in microcalcification induced by cell necrosis [54].

In addition, a form of programmed cell necrosis, called necroptosis, has recently emerged [55] and has been shown to profoundly modulate the development of atherosclerotic plaques [56-58]. The main proteins controlling this form of cell death are receptor-interacting serine/ threonine-protein kinase 1 (RIPK1) and RIPK3 [55]. When activated, RIPK3 phosphorylates mixed-lineage kinase domain-like (MLKL) protein, which triggers MLKL oligomerization, membrane translocation, and formation of a pore allowing the extracellular release of intracellular molecules [59]. MLKL is phosphorylated in advanced but not early human atherosclerotic plaques [58], indicating that necroptosis is effective in advanced human plaque development. Among the different cell types present in plaques and potentially affected by necroptosis, macrophages have been focused in most studies. Macrophage necroptosis is induced in vitro by oxidized LDL and caspase inhibitors [56, 58], and in vivo Ripk3 deletion reduces the number of necrotic macrophages in plaques of ApoE-deficient mice [56]. To our knowledge, whether macrophage necroptosis is associated with plaque calcification has not been addressed specifically, and it was tempting to speculate that necroptosis induces and/or exacerbates calcification by releasing $\mathrm{P}_{\mathrm{i}}$ through MLKL pores. However, the contribution of macrophage necroptosis to plaque development, including calcification and inflammation, might be much more complex than anticipated and difficult to characterize. Surprisingly enough, Ripk3 deletion specifically in macrophages resulted in increased atherosclerotic plaque size [60]. The authors suspected that RIPK3 plays additional roles than promoting necroptosis and particularly antiinflammatory functions explaining the increased lesion development. Additional studies are therefore warranted to have a clearer view of necroptosis impact and its effects on calcification.

Macrophages May Induce Calcification through the Release of Vesicles

Alternatively, or in addition, macrophages may release calcifying extracellular vesicles (EVs). In the aorta of ApoE-deficient mice, electron microscopy demonstrated the presence of crystals in EVs, and near-infrared imaging revealed strong colocalization between macrophages and calcification [48]. EVs released by macrophages may share several features with matrix vesicles (MVs), which are emitted by hypertrophic chondrocytes to initiate apatite crystal nucleation in growth plate cartilage (reviewed in [61]). MVs are released by membrane budding and are thought to accumulate calcium and $\mathrm{P}_{\mathrm{i}}$ in their lumen and to allow the nucleation of the first apatite crystals owing to a nucleation core composed of phosphatidylserine and annexins [62]. In addition, their membrane is enriched with glycosylphosphatidylinositol-anchored tissue-nonspecific alkaline phosphatase (TNAP), the enzyme that hydrolyzes $\mathrm{PP}_{\mathrm{i}}$, allowing crystals that have moved to the extracellular milieu to grow and multiply in association with the collagen matrix [63-65]. In fact, macrophages have been shown to release EVs, which contain phosphatidylserine and annexin V [66], suggesting that they may induce calcification by releasing EVs similar to MVs. Interestingly, in low-density lipoprotein receptor $(L d l r)$ deficient mice, VSMC-specific deletion of RUNX2, the transcription factor governing the differentiation of hypertrophic chondrocytes and osteoblasts, only partly prevents plaque calcification [67], suggesting that other cells than VSMCs transdifferentiated into osteochondrocytelike cells are responsible for calcification in this model. Among the candidate cells, cells expressing CD68, a marker of macrophages, were found to express RUNX2 [67]. This may suggest that macrophages transdifferentiated from VSMCs [4-7] have some RUNX2 activity, or that macrophages can change their phenotype toward a phenotype of mineralizing cells. 
Macrophages May Stimulate VSMCs to Mineralize

Macrophages May Stimulate VSMCs to

Transdifferentiate into Osteochondrocyte-Like Cells

VSMCs in atherosclerotic plaques have the ability to transdifferentiate into osteochondrocyte-like cells. In ApoE-deficient mice, calcification proceeds through a process similar to endochondral ossification, with chondrocyte differentiation [68]. In these mice, like in Ldlrdeficient mice, VSMC-specific deletion of RUNX2 significantly reduces calcification $[67,69]$, demonstrating that VSMCs transdifferentiate to chondrocytes and maybe osteoblasts in order to mineralize plaques. Since the pioneer report by Tintut et al. [70] that TNF-a stimulates VSMCs to express TNAP and mineralize, many articles confirmed that inflammatory cytokines such as TNF- $\alpha$ but also IL- $1 \beta$ or IL- 6 stimulate calcification in VSMC cultures (reviewed in [71]). TNF- $\alpha$ activates VSMCs to transdifferentiate into osteochondrocyte-like cells, expressing the transcription factor RUNX2 and several markers of mineralizing cells [72-74]. Since macrophages stimulate VSMCs to mineralize in part through TNF- $\alpha$ in vitro $[74,75]$, it is likely that VSMCs in plaques are also stimulated to mineralize by TNF- $\alpha$ released from macrophages. Moreover, a recent study suggested that endogenously produced IL- $1 \beta$ is involved in VSMC calcification [76].

Considerable amount of in vitro data demonstrate that inflammatory cytokines stimulate VSMCs to transdifferentiate into chondrocytes, which in turn mature into RUNX2-expressing hypertrophic cells to induce microcalcification owing to their TNAP activity (Fig. 1a). Although this model fits very well with data in mice, it cannot be applied to humans. Indeed, plaque ossification in humans occurs in peripheral arteries but much less in coronaries or carotids [19-21] and relies probably on intramembranous mechanisms (without a cartilage template), rather than on endochondral ones (with a cartilage template) [77]. Moreover, in coronary arteries, expression of osteochondrocyte markers seems to occur after microcalcification, suggesting that VSMC transdifferentiation is a consequence and not a cause of microcalcification $[78,79]$.

Macrophages May Stimulate VSMCs to Calcify Independently from Their Transdifferentiation into Osteochondrocyte-Like Cells

TNF- $\alpha$, and possibly other pro-inflammatory cytokines, may stimulate VSMCs to mineralize independently of their transdifferentiation into mineralizing cells (Fig. 1a). For instance, TNF- $\alpha$ decreases the expression of the $\mathrm{PP}_{\mathrm{i}}$ transporter $\mathrm{ANKH}$ and reduces $\mathrm{PP}_{\mathrm{i}}$ export in VSMCs [80]. This might be sufficient to trigger calcification because genetic deficiency of ANK (the mouse ortholog of ANKH) leads to soft tissue calcification [81]. Moreover, TNF- $\alpha$ decreases extracellular $\mathrm{PP}_{\mathrm{i}}$ levels through TNAP activation [82]. It is worth mentioning that TNAP expression and function are not restricted to $\mathrm{PP}_{\mathrm{i}}$ removal in mineralized tissues, and in particular that TNAP exerts functions in inflammation [83-86]. Interestingly, TNAP expression is stimulated by TNF- $\alpha$ or IL-1 $\beta$ in human mesenchymal stem cells, resulting in increased mineralization, while the expression of RUNX2 and its transcriptional targets is robustly inhibited [87]. In addition, TNF- $\alpha$ may stimulate calcification in VSMCs by decreasing the expression of another important calcification inhibitor, MGP [50, 74, 88].

\section{Microcalcifications Exacerbate Inflammation}

\section{Calcium Phosphate Crystals Activate Macrophages to}

\section{Produce Inflammatory Cytokines}

Calcium phosphate crystals measuring less than $1 \mu \mathrm{m}$ activate macrophages to release TNF- $\alpha$, IL- $1 \beta$, and IL- 8 [89] (Fig. 1b). Crystals are phagocytosed by macrophages [89], and the smallest ones are the most potent to stimulate TNF- $\alpha$ secretion [90], suggesting that they increase TNF- $\alpha$ production at least in part after internalization. While the mechanisms through which crystals activate TNF- $\alpha$ remain obscure, those involved in the secretion of IL- $1 \beta$ are better understood. Crystals activate IL- $1 \beta$ secretion both in human and mouse macrophages through NOD-like receptor family, pyrin domain containing 3 (NLRP3) inflammasome $[91,92]$. NLRP3 consists of an N-terminal pyrin domain (PYD), a central NACHT domain, and a C-terminal leucine-rich repeats (LRR). Upon cellular stress, the LRR domain exposes the NACHT domain that is responsible for homotypic oligomerization, leading to NLRP3 interaction with the adaptor protein ASC, culminating with caspase-1 binding and activation. The latter cleaves the $31-\mathrm{kDa}$ precursor form of IL- $1 \beta$ into its $17-\mathrm{kDa}$ mature form. Caspase- 1 also cleaves gasdermin $\mathrm{D}$, inducing its oligomerization, association with the membrane, and opening of a channel through which IL- $1 \beta$ among other molecules is released extracellularly [93]. Several different organic and inorganic crystals are potent NLRP3 activators, such as monosodium urate, silica, cholesterol crystals, and calcium phosphate crystals. This suggests that it is the inherent repetitive structure of crystals, rather than their composition, that is involved in NLRP3 activation. Crystals are thought 


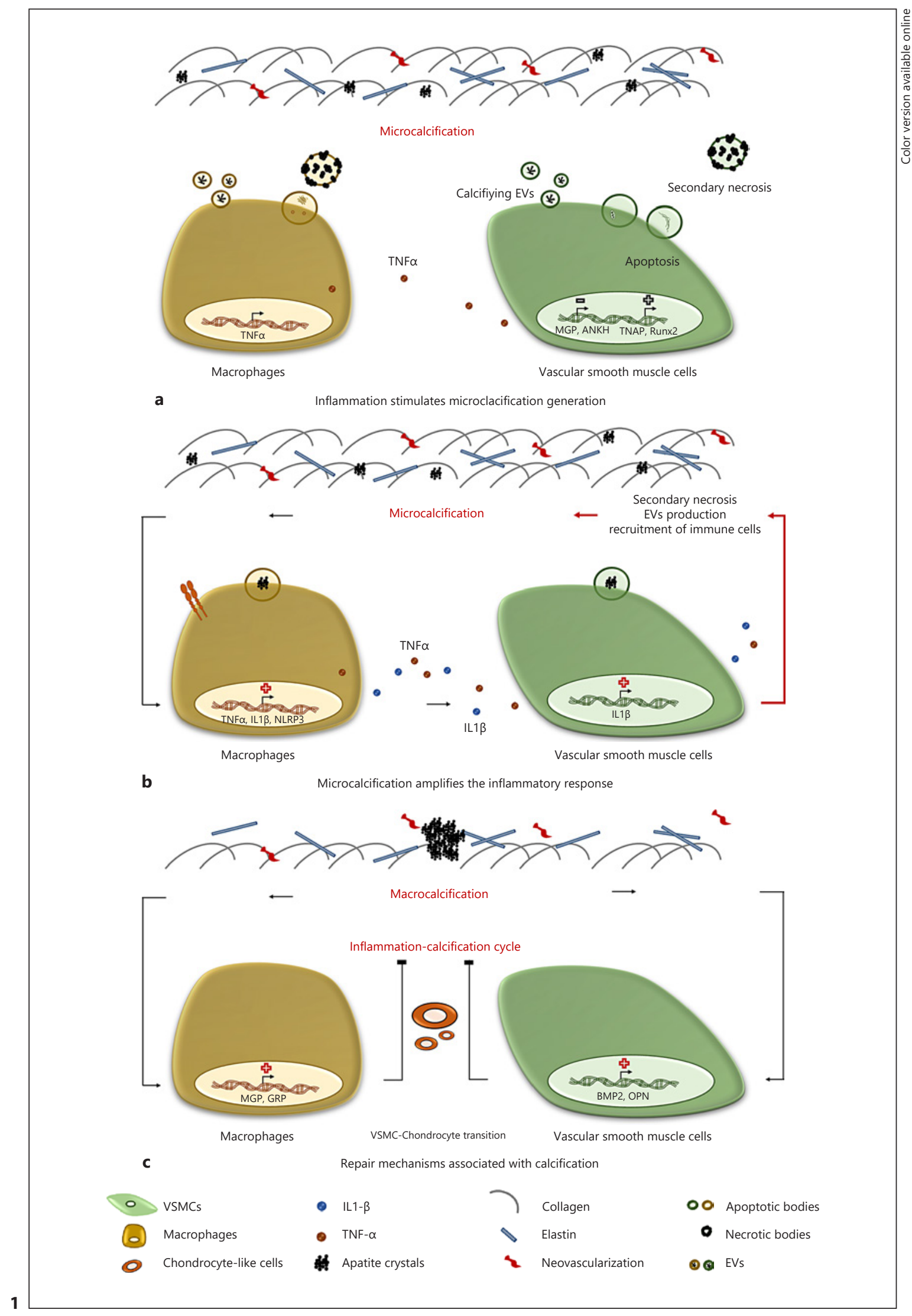

(For legend see next page.) 
to activate NLRP3 by triggering potassium efflux following their internalization [94], but potassium efflux induced by membrane deformation without internalization has also been proposed to be sufficient to activate NLRP3dependent IL-1 $\beta$ production [95]. Thus, macrophages stimulated by crystals may activate VSMCs through the release of inflammatory mediators. Whether they may also stimulate VSMCs to transdifferentiate through the release of receptor activator of NF- $\kappa B$ ligand (RANKL) is a question that merits investigation. Indeed, inhibition of RANKL-RANK signaling with osteoprotegerin reduces plaque calcification [96, 97], and RANKL reverse signaling has recently been shown to activate osteoblast differentiation and bone formation [98].

\section{Calcium Phosphate Crystals Are Pro-Inflammatory on VSMCs}

Although VSMCs are not specialized to secrete proinflammatory molecules, they may secrete cytokines in response to microcalcifications (Fig. 1b). Indeed, similar to macrophages, VSMCs release IL- $1 \beta$ in presence of calcium phosphate crystals [99]. Moreover, VSMCs secrete more IL-1 $\beta$ as they progress toward senescence [99], which occurs frequently in human plaques [100]. In this case, IL-1 $\beta$ release relies on crystal endocytosis and caspase- 1 activity, but maybe not on NLRP3 activation. In fact, other treatments known to activate NLRP3-dependent IL-1 $\beta$ secretion in monocytes/macrophages, such as monosodium urate, nigericin, or ATP, fail to induce IL- $1 \beta$ release in

Fig. 1. Inflammation and microcalcification in the context of atherosclerosis: a vicious cycle. a Inflammation stimulates microcalcification generation. Inflammation is a key factor that activates calcification formation. Immune cells such as M1 macrophages are key players inducing apatite crystals generation and thus ectopic calcification initiation. For instance, these cells produce calcifying EVs and undergo secondary necrosis due to compromised clearance of apoptotic bodies [11, 21, 66]. Moreover, macrophages stimulate VSMCs reprogramming through liberation of pro-inflammatory cytokines such as TNF- $\alpha$. The latter creates an imbalance in favor of calcification promoters such as RUNX2 [70, $72,74]$ and TNAP $[70,73]$. On the other hand, MGP and ANKH calcification inhibitors are downregulated [73]. Importantly, VSMCs can also produce calcifying EVs and undergo secondary necrosis. b Microcalcification amplifies the inflammatory response. Once initiated, microcalcifications exaggerate the inflammatory response in the context of a positive feedback loop that boosts the mineralization process. In fact, endocytosis of calcium phosphate crystals increases the production of pro-inflammatory mediators by M1 macrophages, such as TNF- $\alpha$ and IL-1 $\beta[89,90]$. Moreover, NLRP3 inflammasome activation by crystals is known to facilitate IL- $1 \beta$ liberation, by macrophages and VSMCs $[91,92,99]$. Taken together, the resulting pro-inflammatory response amplifies
VSMCs [99]. In addition to triggering IL-1 $\beta$ secretion, long-term treatment of human VSMCs with calcium phosphate crystals triggers crystal endocytosis and induces cell death [101]. VSMC apoptotic death is frequently followed by secondary necrosis and the release of the alarmin IL-1 $\alpha$, which exacerbates plaque inflammation [102]. Finally, in a last pathological step, apoptotic bodies released by dying VSMCs may constitute a nidus for new calcification to occur [103], further amplifying inflammation.

\section{An Unstoppable Vicious Cycle of Calcification and Inflammation, or Efforts to Resolve Inflammation and Repair?}

\section{Macrophages and VSMCs Try to Stop Pathological Calcification and Remove Crystals}

Monocytes and macrophages were recently shown to produce $\gamma$-carboxylated MGP and Gla-rich protein (GRP) [104] (Fig. 1c). Indeed, not only MGP but also GRP acts as an inhibitor of vascular calcification [105, 106]. Moreover, macrophages release more GRP and MGP in addition to producing more $\gamma$-glutamyl carboxylase, the enzyme responsible for their $\gamma$-carboxylation, in presence of inflammatory molecules or hydroxyapatite crystals [104]. It is largely conceivable that the same effects occur in human atherosclerotic plaques, where the presence of microcalcifications correlate with that of macrophages and carboxylated MGP [78, 79]. In addition,

several processes related to microcalcification formation including increased immune cells recruitment, secondary necrosis, and EVs production. c Repair mechanisms associated with calcification. The terminal phase of atherosclerosis is linked with the formation of relatively large and stable calcification deposits that are thought to resolve inflammation. Under such circumstances, macrophages and VSMCs possibly generate calcification inhibitors including MGP, GRP, and OPN to prevent additional crystal growth and formation of new calcification sites [104, 107, 108]. On the other hand, VSMCs produce BMP2 which, most probably, activates the transition of VSMCs into chondrocytes resulting into a cartilage-like environment that ensures the stability of the calcified tissue $[107,114,115]$. Taken together, these processes are expected to break the vicious inflammation-calcification cycle. Therefore, a focus toward a better understanding of mineralization repair mechanisms is of great importance to limit the risk of atherosclerosis-induced mortality. ANKH, progressive ankylosis protein homolog; BMP2, bone morphogenetic protein 2; EVs, extracellular vesicles; GRP, Gla-rich protein; IL-1 $\beta$, interleukin$1 \beta$; MGP, matrix Gla protein; NLRP3, nod-like receptor protein 3; OPN, osteopontin; RUNX2, runt-related transcription factor 2; TNAP, tissue-nonspecific alkaline phosphatase; TNF- $\alpha$, tumor necrosis factor- $\alpha$; VSMCs, vascular smooth muscle cells. 
VSMCs also produce osteopontin (OPN) in response to calcium phosphate crystals $[107,108]$. OPN is an inducible inhibitor of ectopic calcification [109], whose activity relies on its phosphorylation status [110]. Phosphorylated OPN binds to crystals and inhibits their growth. OPN stimulates macrophages to phagocyte crystals [111], like it stimulates osteoclasts to promote bone resorption [112]. Logically, OPN deficiency in ApoE-deficient atherosclerotic mice leads to the development of more calcified plaques [113].

\section{Crystals Induce VSMCs to Transdifferentiate into Chondrocytes to Build Cartilage}

If as explained above crystals exert pro-inflammatory effects on VSMCs, they also stimulate VSMCs to produce cartilage to repair a disorganized calcified tissue (Fig. 1c). Apatite crystals stimulate VSMCs to produce BMP2, a potent bone anabolic growth factor $[107,114,115]$. Inhibition of endogenous BMP2 effects by the addition of Noggin in VSMC cultures results in blocking the increase in chondrocyte markers stimulated by apatite crystals [115]. The shape of the latter may have little importance since rods, needles, plates, or spheres all increased RUNX2 protein levels [108]. Interestingly, not only does the MGP knockout mouse model leads to vascular calcification in absence of atherosclerosis, but also it leads to cartilage metaplasia in the vasculature [50]. A thorough time-course examination of arterial calcification revealed that chondrocytes differentiate after initiation of calcification [116], suggesting that cartilage metaplasia is a cellular response permitting the transformation of a pathologically, pro-inflammatory calcified tissue into a more stable one (Fig. 2).

\section{Crystal Induction of Inflammation and Cartilage \\ Formation: Any Similarity with Bone Fracture \\ Healing?}

The evolution from a disorganized, pro-inflammatory tissue containing apatite crystals toward building a new mineralized tissue may not only occur in atherosclerosis

Fig. 2. Macrophages and atherosclerosis evolution: a general overview. a Progressive atherosclerotic lesion. During the course of atherosclerosis, macrophages (namely, the M1 phenotype) activate several mechanisms to ensure the initiation and progression of the disease. These immune cells are known to engulf oxidized LDL and to form foam cells. In addition, they can produce pro-inflammatory cytokines, activate the deregulation of extracellular matrix, and secrete EVs. Moreover, M1 cells are characterized by defective efferocytosis and increased secondary necrosis. Taken together, these processes are thought to launch microcalcification formation. On the other hand, VSMCs can also change into osteoblast-like cells, plaques but also in the bone after a fracture. Indeed, fracture healing initiates with an early inflammatory phase, which takes place just after the fracture, and is necessary to induce ossification thereafter [117]. Absence of TNF- $\alpha$ in particular delays ossification [118], in part by delaying chondrocyte differentiation [119]. Interestingly, TNF- $\alpha$ may act mainly through BMP2 since TNF- $\alpha$ stimulates BMP2 expression in chondrocytes [120] and endothelial cells [121], and since the absence of BMP2 blocks fracture healing in its early steps [122]. Therefore, it is possible that the inflammatory effects of apatite crystals in atherosclerosis plaques are necessary to generate osteochondrocyte-like cells that will produce large mineralized surfaces allowing plaque stabilization. The recent histological study in human carotids published by Montanaro et al. [28] suggests that TGF- $\beta$ expressed by M2 macrophages may also link the resolution of inflammation to the differentiation of osteochondrocyte-like cells and the growth of macrocalcifications. Therefore, M1 macrophages may participate in the vicious cycle linking microcalcification to inflammation, whereas M2 macrophages may contribute to terminate this cycle and allow plaque repair through ossification. The localization of macrophages in atherosclerotic plaques supports this hypothesis. The pro-inflammatory M1 cells are located in unstable rupture-prone plaque while the anti-inflammatory M2 macrophages are mostly present in vascular adventitia, far from the lipid core, and more stable regions of the plaque [123-125]. M1 macrophages show increased lipid accumulation, mitochondrial dysfunction, destabilized lysosomes, activated oxidative stress, defective efferocytosis, and elevated release of pro-inflammatory mediators such as IL-6, IL12 , IL- $1 \beta$, and TNF- $\alpha$, as well as ROS. On the other hand, M2 cells enclose small lipid droplets and are supposed to stimulate atherosclerosis regression through several mechanisms including supplementation of anti-inflammatory factors (IL-10 and TGF- $\beta$ ), clearance of dying cells through efferocytosis, and tissue repair following

thus promoting additional crystal deposition. It is worth noting that a thin fibrous cap is a major feature of an unstable ruptureprone lesion. b Stable atherosclerotic lesion. It is believed that the transition of VSMCs into osteoblast-like cells is induced by M2 macrophages to form macrocalcification deposits. In this context, M2 cells have been reported to generate calcification inhibitors, accumulate smaller lipid droplets, produce anti-inflammatory mediators, activate clearance of apoptotic debris, and accelerate tissue repair via stimulating angiogenesis, chondrocyte formation, and fibrosis. EVs, extracellular vesicles; IL- $1 \beta$, interleukin- $1 \beta$; TNF- $\alpha$, tumor necrosis factor- $\alpha$; VSMCs, vascular smooth muscle cells.

(For figure see next page.) 


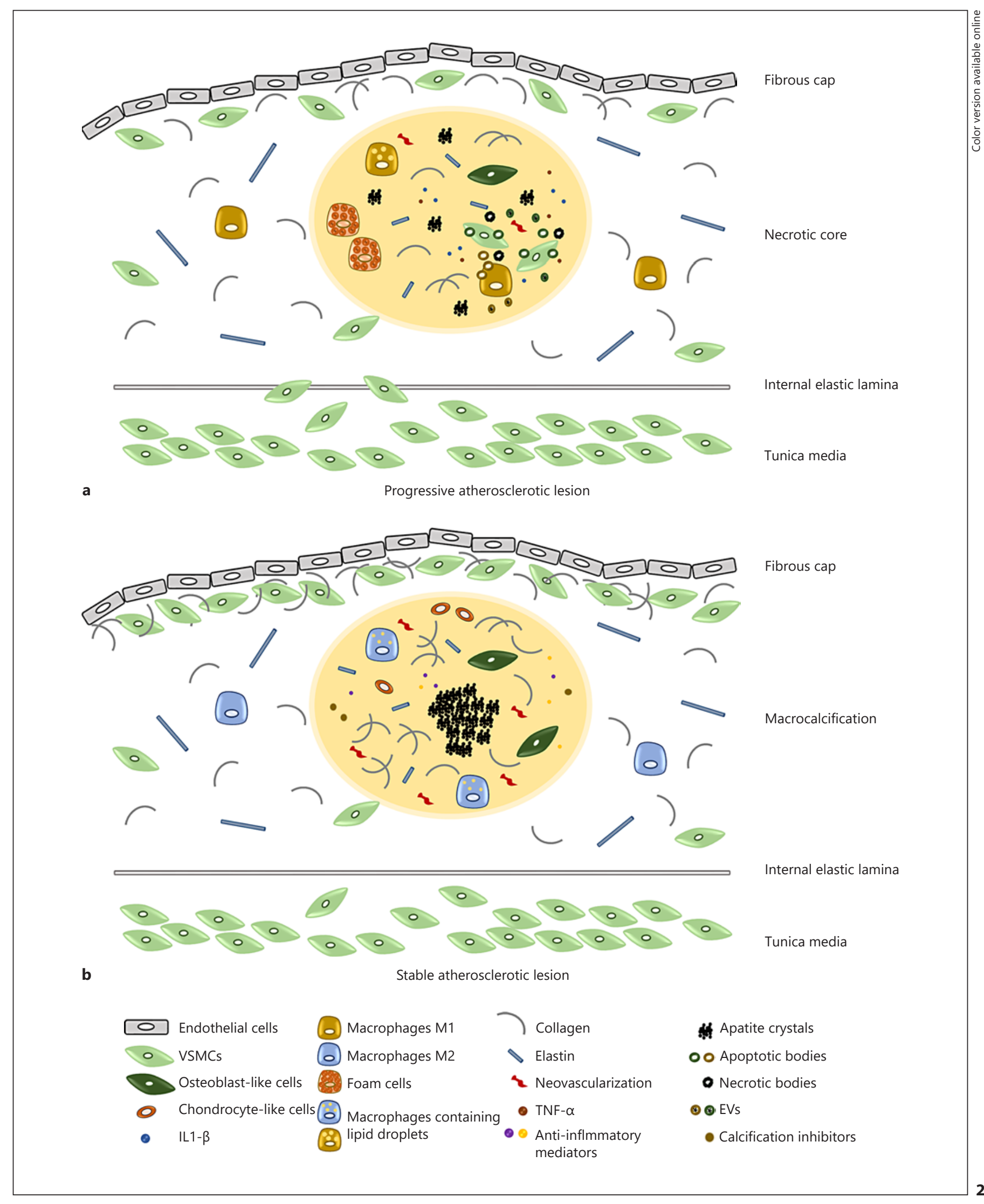

Inflammation and Microcalcification 
collagen formation and angiogenesis [126]. Collectively, these data suggest that the balance between M1 and M2 macrophages might play a crucial role in the transition from pro-inflammatory plaques with microcalcifications to resolution of inflammation associated with plaque macrocalcification. Interestingly, a similar role for M1 and M2 macrophages is also strongly suspected during bone fracture healing (reviewed in [127]).

We consider important in future experiments to thoroughly characterize how inflammation, calcification, and/or ossification are interconnected in atherosclerotic plaques. The emerging treatments targeting IL- $1 \beta$ will likely impact this association, with beneficial and/or detrimental consequences. Anti-IL-1 $\beta$ therapies are efficient in reducing inflammation and calcification in mice [128] as well as recurrent cardiovascular events in patients [129]. However, a recent study indicated that IL-1 $\beta$ inhibition induces negative effects on advanced atherosclerotic plaques and that IL- $1 \beta$ exerts its protective effects acting both on VSMCs and macrophages [130]. Whether calcification is impacted differently when IL- $1 \beta$ is inhibited in early versus advanced plaques is not known but deserves particular attention.

In conclusion, a huge amount of data highlight the strong interrelationship between inflammation and calcification in atherosclerotic plaques, with inflammation playing an important role in calcium deposition and calcifications exacerbating inflammation. However, efforts still remain to be done to better understand whether and how inflammation, or its resolution, impacts plaque macrocalcification leading to plaque stabilization.

\section{Conflict of Interest Statement}

The authors have no conflicts of interest to declare.

\section{Funding Sources}

We acknowledge financial support from the European Research Area Network on Cardiovascular Diseases (ERA-NET CVD, Microexploration project 2018-2021) to work on atherosclerotic plaque microcalcification.

\section{Author Contributions}

D.M. designed the article, wrote most chapters, and revised the manuscript; L.K. wrote the chapter on atherosclerosis inflammation; L.B. reviewed the article and wrote the part on VSMC phenotypic changes; H.I. drew the figures; E.H. and K.Z. wrote the chapter on M1/M2 macrophages and revised the manuscript.

\section{References}

1 Ross R. Atherosclerosis: an inflammatory disease. N Engl J Med. 1999 Jan 14;340(2): $115-26$.

2 Ghattas A, Griffiths HR, Devitt A, Lip GY, Shantsila E. Monocytes in coronary artery disease and atherosclerosis: where are we now? J Am Coll Cardiol. 2013 Oct;62(17): 1541-51.

3 Rong JX, Shapiro M, Trogan E, Fisher EA. Transdifferentiation of mouse aortic smooth muscle cells to a macrophage-like state after cholesterol loading. Proc Natl Acad Sci U S A. 2003 Nov 11;100(23):13531-6.

4 Allahverdian S, Chehroudi AC, McManus BM, Abraham T, Francis GA. Contribution of intimal smooth muscle cells to cholesterol accumulation and macrophage-like cells in human atherosclerosis. Circulation. 2014 Apr 15;129(15):1551-9.

5 Feil S, Fehrenbacher B, Lukowski R, Essmann F, Schulze-Osthoff K, Schaller M, et al. Transdifferentiation of vascular smooth muscle cells to macrophage-like cells during atherogenesis. Circ Res. 2014 Sep 12;115(7): 662-7.

6 Shankman LS, Gomez D, Cherepanova OA, Salmon M, Alencar GF, Haskins RM, et al.
KLF4-dependent phenotypic modulation of smooth muscle cells has a key role in atherosclerotic plaque pathogenesis. Nat Med. 2015 Jun;21(6):628-37.

7 Wang Y, Dubland JA, Allahverdian S, Asonye E, Sahin B, Jaw JE, et al. Smooth muscle cells contribute the majority of foam cells in ApoE (Apolipoprotein E)-deficient mouse atherosclerosis. Arterioscler Thromb Vasc Biol. 2019 May;39(5):876-87.

8 Ivanova EA, Bobryshev YV, Orekhov AN. Intimal pericytes as the second line of immune defence in atherosclerosis. World J Cardiol. 2015 Oct 26;7(10):583-93.

9 Legein B, Temmerman L, Biessen EA, Lutgens E. Inflammation and immune system interactions in atherosclerosis. Cellular and molecular life sciences. Cell Mol Life Sci. 2013 Oct;70(20): 3847-69.

10 Feng B, Yao PM, Li Y, Devlin CM, Zhang D, Harding HP, et al. The endoplasmic reticulum is the site of cholesterol-induced cytotoxicity in macrophages. Nat Cell Biol. 2003 Sep;5(9): 781-92.

11 Schrijvers DM, De Meyer GR, Kockx MM, Herman AG, Martinet W. Phagocytosis of apoptotic cells by macrophages is impaired in atherosclerosis. Arterioscler Thromb Vasc Biol. 2005 Jun;25(6):1256-61.

12 Amento EP, Ehsani N, Palmer H, Libby P. Cytokines and growth factors positively and negatively regulate interstitial collagen gene expression in human vascular smooth muscle cells. Arterioscler Thromb. 1991 Sep-Oct; 11(5):1223-30

13 Sukhova GK, Schönbeck U, Rabkin E, Schoen FJ, Poole AR, Billinghurst RC, et al. Evidence for increased collagenolysis by interstitial collagenases- 1 and - 3 in vulnerable human atheromatous plaques. Circulation. 1999 May;99(19): 2503-9.

14 Horton DB, Libby P, Schonbeck U. Ligation of CD40 onvascular smooth muscle cells mediates loss of interstitial collagen via matrix metalloproteinase activity. Ann N Y Acad Sci. 2001 Dec;947:329-36.

15 Sage AP, Tintut Y, Demer LL. Regulatory mechanisms in vascular calcification. Nat Rev Cardiol. 2010 Sep;7(9):528-36.

16 Doherty TM, Fitzpatrick LA, Inoue D, Qiao JH, Fishbein MC, Detrano RC, et al. Molecular, endocrine, and genetic mechanisms of arterial calcification. Endocr Rev. 2004 Aug. 25(4):629-72. 
17 Greenland P, LaBree L, Azen SP, Doherty TM, Detrano RC. Coronary artery calcium score combined with Framingham score for risk prediction in asymptomatic individuals. JAMA. 2004 Jan;291(2):210-5.

18 Agatston AS, Janowitz WR, Kaplan G, Gasso J, Hildner F, Viamonte M. Ultrafast computed tomography-detected coronary calcium reflects the angiographic extent of coronary arterial atherosclerosis. Am J Cardiol. 1994 Dec;74(12):1272-4.

19 Herisson F, Heymann MF, Chétiveaux M, Charrier C, Battaglia S, Pilet P, et al. Carotid and femoral atherosclerotic plaques show different morphology. Atherosclerosis. 2011 Jun;216(2):348-54.

20 Mori H, Torii S, Kutyna M, Sakamoto A, Finn AV, Virmani R. Coronary artery calcification and its progression: what does it really mean? JACC Cardiovasc Imaging. 2018 01;11(1): $127-42$.

21 Jinnouchi H, Sato Y, Sakamoto A, Cornelissen A, Mori M, Kawakami R, et al. Calcium deposition within coronary atherosclerotic lesion: implications for plaque stability. Atherosclerosis. 2020 Jun;306:85-95.

22 Kelly-Arnold A, Maldonado N, Laudier D, Aikawa E, Cardoso L, Weinbaum S. Revised microcalcification hypothesis for fibrous cap rupture in human coronary arteries. Proc Natl Acad Sci U S A. 2013 Jun;110(26): 10741-6.

23 Pugliese G, Iacobini C, Blasetti Fantauzzi C, Menini S. The dark and bright side of atherosclerotic calcification. Atherosclerosis. 2015 Feb;238(2):220-30.

24 Shi X, Gao J, Lv Q, Cai H, Wang F, Ye R, et al. Calcification in atherosclerotic plaque vulnerability: friend or foe? Front Physiol. 2020 11:56.

25 Ehara S, Kobayashi Y, Yoshiyama M, Shimada K, Shimada Y, Fukuda D, et al. Spotty calcification typifies the culprit plaque in patients with acute myocardial infarction: an intravascular ultrasound study. Circulation. 2004 Nov;110(22):3424-9.

26 Mizukoshi M, Kubo T, Takarada S, Kitabata $\mathrm{H}$, Ino $\mathrm{Y}$, Tanimoto $\mathrm{T}$, et al. Coronary superficial and spotty calcium deposits in culprit coronary lesions of acute coronary syndrome as determined by optical coherence tomography. Am J Cardiol. 2013 Jul;112(1):34-40.

27 Sakaguchi M, Hasegawa T, Ehara S, Matsumoto K, Mizutani K, Iguchi T, et al. New insights into spotty calcification and plaque rupture in acute coronary syndrome: an optical coherence tomography study. Heart Vessels. 2016 Dec;31(12):1915-22.

28 Montanaro M, Scimeca M, Anemona L, Servadei $\mathrm{F}$, Giacobbi E, Bonfiglio R, et al. The paradox effect of calcification in carotid atherosclerosis: microcalcification is correlated with plaque instability. Int J Mol Sci. 2021 Jan; 22(1):395.

29 Schwartz GG, Olsson AG, Ezekowitz MD, Ganz P, Oliver MF, Waters D, et al. Effects of atorvastatin on early recurrent ischemic events in acute coronary syndromes: the MIRACL study - a randomized controlled trial. JAMA. 2001 Apr;285(13):1711-8.

30 Cannon CP, Braunwald E, McCabe CH, Rader DJ, Rouleau JL, Belder R, et al. Intensive versus moderate lipid lowering with statins after acute coronary syndromes. N Engl J Med. 2004 Apr;350(15):1495-504.

31 Banach M, Serban C, Sahebkar A, Mikhailidis DP, Ursoniu S, Ray KK, et al. Impact of statin therapy on coronary plaque composition: a systematic review and meta-analysis of virtual histology intravascular ultrasound studies. BMC Med. 2015 Sep;13:229.

32 Puri R, Nicholls SJ, Shao M, Kataoka Y, Uno K, Kapadia SR, et al. Impact of statins on serial coronary calcification during atheroma progression and regression. J Am Coll Cardiol. 2015 Apr;65(13):1273-82.

33 Nakazato R, Gransar H, Berman DS, Cheng VY, Lin FY, Achenbach S, et al. Statins use and coronary artery plaque composition: results from the international multicenter CONFIRM registry. Atherosclerosis. 2012 Nov;225(1): $148-53$.

34 Lee SE, Chang HJ, Sung JM, Park HB, Heo R, Rizvi A, et al. Effects of statins on coronary atherosclerotic plaques: the PARADIGM Study. JACC Cardiovasc Imaging. 2018 Oct; 11(10):1475-84.

35 Mujaj B, Bos D, Selwaness M, Leening MJG, Kavousi M, Wentzel JJ, et al. Statin use is associated with carotid plaque composition: the Rotterdam Study. Int J Cardiol. 2018 Jun;260: 213-8.

36 Lee SE, Sung JM, Andreini D, Budoff MJ, Cademartiri F, Chinnaiyan K, et al. Differential association between the progression of coronary artery calcium score and coronary plaque volume progression according to statins: the Progression of AtheRosclerotic PlAque DetermIned by Computed TomoGraphic Angiography Imaging (PARADIGM) Study. Eur Heart J Cardiovasc Imaging. 2019 Nov;20(11):1307-14.

37 Healy A, Berus JM, Christensen JL, Lee C, Mantsounga C, Dong W, et al. Statins disrupt macrophage Racl regulation leading to increased atherosclerotic plaque calcification. Arterioscler Thromb Vasc Biol. 2020 Mar;40(3): 714-32.

38 Xian JZ, Lu M, Fong F, Qiao R, Patel NR, Abeydeera $\mathrm{D}$, et al. Statin effects on vascular calcification: microarchitectural changes in aortic calcium deposits in aged hyperlipidemic mice. Arterioscler Thromb Vasc Biol. 2021 Apr;41(4):e185-92.

39 Huang H, Virmani R, Younis H, Burke AP, Kamm RD, Lee RT. The impact of calcification on the biomechanical stability of atherosclerotic plaques. Circulation. 2001 Feb;103(8): 1051-6.

40 Vengrenyuk Y, Carlier S, Xanthos S, Cardoso L, Ganatos P, Virmani R, et al. A hypothesis for vulnerable plaque rupture due to stress-induced debonding around cellular microcalcifications in thin fibrous caps. Proc
Natl Acad Sci U S A. 2006 Oct;103(40): 14678-83.

41 Joshi NV, Vesey AT, Williams MC, Shah AS, Calvert PA, Craighead FH, et al. 18F-fluoride positron emission tomography for identification of ruptured and high-risk coronary atherosclerotic plaques: a prospective clinical trial. Lancet. 2014;383(9918):705-13.

42 Reith S, Milzi A, Dettori R, Marx N, Burgmaier M. Predictors for target lesion microcalcifications in patients with stable coronary artery disease: an optical coherence tomography study. Clin Res Cardiol. 2018 Sep;107(9): 763-71.

43 Shaalan WE, Cheng H, Gewertz B, McKinsey JF, Schwartz LB, Katz D, et al. Degree of carotid plaque calcification in relation to symptomatic outcome and plaque inflammation. J Vasc Surg. 2004 Aug;40(2):262-9.

44 Mauriello A, Servadei F, Zoccai GB, Giacobbi E, Anemona L, Bonanno E, et al. Coronary calcification identifies the vulnerable patient rather than the vulnerable Plaque. Atherosclerosis. 2013 Jul;229(1):124-9.

45 Hénaut L, Candellier A, Boudot C, Grissi M, Mentaverri R, Choukroun G, et al. New insights into the roles of monocytes/macrophages in cardiovascular calcification associated with chronic kidney disease. Toxins. 2019 Sep;11(9):529.

46 Abdelbaky A, Corsini E, Figueroa AL, Fontanez S, Subramanian S, Ferencik M, et al. Focal arterial inflammation precedes subsequent calcification in the same location: a Longitudinal FDG-PET/CT Study. Circ Cardiovasc Imaging. 2013 Jul;6(5):747-54.

47 Van der Heiden K, Barrett HE, Meester EJ, van Gaalen K, Krenning BJ, Beekman FJ, et al. SPECT/CT imaging of inflammation and calcification in human carotid atherosclerosis to identify the plaque at risk of rupture. J Nucl Cardiol. 2021 Jul 27.

48 Aikawa E, Nahrendorf M, Figueiredo JL, Swirski FK, Shtatland T, Kohler RH, et al. Osteogenesis associates with inflammation in early-stage atherosclerosis evaluated by molecular imaging in vivo. Circulation. 2007 Dec;116(24):2841-50.

49 Kim KM. Apoptosis and calcification. Scanning Microsc. 1995;9(4):1137-8; discussion 75-8.

50 Luo G, Ducy P, McKee MD, Pinero GJ, Loyer E, Behringer RR, et al. Spontaneous calcification of arteries and cartilage in mice lacking matrix GLA protein. Nature. 1997 Mar; 386(6620):78-81.

51 Nitschke Y, Baujat G, Botschen U, Wittkampf T, du Moulin M, Stella J, et al. Generalized arterial calcification of infancy and pseudoxanthoma elasticum can be caused by mutations in either ENPP1 or ABCC6. Am J Hum Genet. 2012 Jan;90(1):25-39.

52 Romero-Garcia S, Prado-Garcia H. Mitochondrial calcium: transport and modulation of cellular processes in homeostasis and cancer (Review). Int J Once. 2019 Apr;54(4): 1155-67. 
53 Bäck M, Michel JB. From organic and inorganic phosphates to valvular and vascular calcifications. Cardiovasc Res. 2021 Jul 27; 117(9):2016-29.

54 Coscas R, Bensussan M, Jacob MP, Louedec L, Massy Z, Sadoine J, et al. Free DNA precipitates calcium phosphate apatite crystals in the arterial wall in vivo. Atherosclerosis. 2017 Apr;259:60-7.

55 Choi ME, Price DR, Ryter SW, Choi AMK. Necroptosis: a crucial pathogenic mediator of human disease. JCI Insight. 2019 Aug;4(15): e128834.

56 Lin J, Li H, Yang M, Ren J, Huang Z, Han F, et al. A role of RIP3-mediated macrophage necrosis in atherosclerosis development. Cell Rep. 2013 Jan;3(1):200-10.

57 Meng L, Jin W, Wang X. RIP3-mediated necrotic cell death accelerates systematic inflammation and mortality. Proc Natl Acad Sci U S A. 2015 Sep;112(35):11007-12.

58 Karunakaran D, Geoffrion M, Wei L, Gan W, Richards L, Shangari P, et al. Targeting macrophage necroptosis for therapeutic and diagnostic interventions in atherosclerosis. Sci Adv. 2016 Jul;2(7):e1600224.

59 Kolbrink B, Riebeling T, Kunzendorf U, Krautwald S. Plasma membrane pores drive inflammatory cell death. Front Cell Dev Biol. 2020;8:817.

60 Colijn S, Muthukumar V, Xie J, Gao S, Griffin CT. Cell-specific and athero-protective roles for RIPK3 in a murine model of atherosclerosis. Dis Model Mech. 2020 Jan;13(1): dmm041962.

61 Bottini M, Mebarek S, Anderson KL, Strzelecka-Kiliszek A, Bozycki L, Simão AMS, et al. Matrix vesicles from chondrocytes and osteoblasts: their biogenesis, properties, functions and biomimetic models. Biochim Biophys Acta Gen Subj. 2018 Mar;1862(3):532-46.

62 Wu LN, Yoshimori T, Genge BR, Sauer GR, Kirsch T, Ishikawa Y, et al. Characterization of the nucleational core complex responsible for mineral induction by growth plate cartilage matrix vesicles. J Biol Chem. 1993 Nov; 268(33):25084-94.

63 Hessle L, Johnson KA, Anderson HC, Narisawa S, Sali A, Goding JW, et al. Tissue-nonspecific alkaline phosphatase and plasma cell membrane glycoprotein- 1 are central antagonistic regulators of bone mineralization. Proc Natl Acad Sci U S A. 2002 Jul;99(14): 9445-9.

64 Harmey D, Hessle L, Narisawa S, Johnson KA, Terkeltaub R, Millán JL. Concerted regulation of inorganic pyrophosphate and osteopontin by akp2, enpp1, and ank: an integrated model of the pathogenesis of mineralization disorders. Am J Pathol. 2004 Apr;164(4):1199209.

65 Murshed M, Harmey D, Millán JL, McKee MD, Karsenty G. Unique coexpression in osteoblasts of broadly expressed genes accounts for the spatial restriction of ECM mineralization to bone. Genes Dev. 2005 May;19(9):1093-104.
66 New SE, Goettsch C, Aikawa M, Marchini JF, Shibasaki M, Yabusaki K, et al. Macrophagederived matrix vesicles: an alternative novel mechanism for microcalcification in atherosclerotic plaques. Circ Res. 2013 Jun;113(1): 72-7.

67 Lin ME, Chen TM, Wallingford MC, Nguyen NB, Yamada S, Sawangmake C, et al. Runx2 deletion in smooth muscle cells inhibits vascular osteochondrogenesis and calcification but not atherosclerotic lesion formation. Cardiovasc Res. 2016 Nov; 112(2):606-16

68 Rattazzi M, Bennett BJ, Bea F, Kirk EA, Ricks JL, Speer M, et al. Calcification of advanced atherosclerotic lesions in the innominate arteries of ApoE-deficient mice: potential role of chondrocyte-like cells. Arterioscler Thromb Vasc Biol. 2005 Jul; 25(7):1420-5.

69 Sun Y, Byon CH, Yuan K, Chen J, Mao X, Heath JM, et al. Smooth muscle cell-specific runx2 deficiency inhibits vascular calcification. Circ Res. 2012 Aug; 111(5):543-52.

70 Tintut Y, Patel J, Parhami F, Demer LL. Tumor necrosis factor-alpha promotes in vitro calcification of vascular cells via the cAMP pathway. Circulation. 2000 Nov; 102(21): 2636-42.

71 Bessueille L, Magne D. Inflammation: a culprit for vascular calcification in atherosclerosis and diabetes. Cell Mol Life Sci. 2015 Mar; 72(13):2475-89.

72 Villa-Bellosta R, Levi M, Sorribas V. Vascular smooth muscle cell calcification and SLC20 inorganic phosphate transporters: effects of PDGF, TNF-alpha, and Pi. Pflugers Arch. 2009 Oct;458(6):1151-61.

73 Lee HL, Woo KM, Ryoo HM, Baek JH. Tumor necrosis factor-alpha increases alkaline phosphatase expression in vascular smooth muscle cells via MSX2 induction. Biochem Biophys Res Commun. 2010 Jan;391(1): 1087-92.

74 Deuell KA, Callegari A, Giachelli CM, Rosenfeld ME, Scatena M. RANKL enhances macrophage paracrine pro-calcific activity in high phosphate-treated smooth muscle cells: dependence on IL- 6 and TNF- $\alpha$. J Vasc Res. 2012;49(6):510-21.

75 Shioi A, Katagi M, Okuno Y, Mori K, Jono S, Koyama $\mathrm{H}$, et al. Induction of bone-type alkaline phosphatase in human vascular smooth muscle cells: roles of tumor necrosis factor-alpha and oncostatin $\mathrm{M}$ derived from macrophages. Circ Res. 2002 Jul; 91(1):9-16.

76 Wen C, Yang X, Yan Z, Zhao M, Yue X, Cheng $X$, et al. Nalp3 inflammasome is activated and required for vascular smooth muscle cell calcification. Int J Cardiol. 2013 Oct; 168(3):2242-7

77 Aigner T, Neureiter D, Câmpean V, Soder S, Amann K. Expression of cartilage-specific markers in calcified and non-calcified atherosclerotic lesions. Atherosclerosis. 2008 Jan; 196(1):37-41.
78 Roijers RB, Debernardi N, Cleutjens JP, Schurgers LJ, Mutsaers PH, van der Vusse GJ. Microcalcifications in early intimal lesions of atherosclerotic human coronary arteries. Am J Pathol. 2011 Jun;178(6):2879-87.

79 Chatrou ML, Cleutjens JP, van der Vusse GJ, Roijers RB, Mutsaers PH, Schurgers LJ. Intrasection analysis of human coronary arteries reveals a potential role for micro-calcifications in macrophage recruitment in the early stage of atherosclerosis. PLoS One. 2015; 10(11): 0142335

80 Zhao G, Xu MJ, Zhao MM, Dai XY, Kong W, Wilson GM, et al. Activation of nuclear factor-kappa B accelerates vascular calcification by inhibiting ankylosis protein homolog expression. Kidney Int. 2012 Jul;82(1):34-44.

81 Ho AM, Johnson MD, Kingsley DM. Role of the mouse ank gene in control of tissue calcification and arthritis. Science. $2000 \mathrm{Jul}$; 289(5477):265-70.

82 Lencel P, Delplace S, Pilet P, Leterme D, Miellot F, Sourice S, et al. Cell-specific effects of TNF- $\alpha$ and IL-1 $\beta$ on alkaline phosphatase: implication for syndesmophyte formation and vascular calcification. Lab Invest. 2011 Oct;91(10):1434-42.

83 Pettengill M, Robson S, Tresenriter M, Millán JL, Usheva A, Bingham T, et al. Soluble ecto$5^{\prime}$-nucleotidase $\left(5^{\prime}\right.$-NT), alkaline phosphatase, and adenosine deaminase (ADA1) activities in neonatal blood favor elevated extracellular adenosine. J Biol Chem. 2013 Sep; 288(38):27315-26.

84 Pettengill M, Matute JD, Tresenriter M, Hibbert J, Burgner D, Richmond P, et al. Human alkaline phosphatase dephosphorylates microbial products and is elevated in preterm neonates with a history of late-onset sepsis. PLoS One. 2017;12(4):e0175936.

85 Gámez-Belmonte R, Hernández-Chirlaque C, Sánchez de Medina F, Martínez-Augustin O. Experimental acute pancreatitis is enhanced in mice with tissue nonspecific alkaline phoshatase haplodeficiency due to modulation of neutrophils and acinar cells. Biochim Biophys Acta Mol Basis Dis. 2018 Nov; 1864(11):3769-79.

86 Bessueille L, Briolay A, Como J, Mebarek S, Mansouri C, Gleizes M, et al. Tissue-nonspecific alkaline phosphatase is an anti-inflammatory nucleotidase. Bone. 2020 Apr;133: 115262.

87 Ding J, Ghali O, Lencel P, Broux O, Chauveau C, Devedjian JC, et al. TNF-alpha and IL1beta inhibit RUNX2 and collagen expression but increase alkaline phosphatase activity and mineralization in human mesenchymal stem cells. Life Sci. 2009 Apr;84(15-16): 499-504.

88 Ikeda K, Souma Y, Akakabe Y, Kitamura Y, Matsuo K, Shimoda Y, et al. Macrophages play a unique role in the plaque calcification by enhancing the osteogenic signals exerted by vascular smooth muscle cells. Biochem Biophys Res Commun. 2012 Aug;425(1):3944. 
89 Nadra I, Mason JC, Philippidis P, Florey O, Smythe CD, McCarthy GM, et al. Proinflammatory activation of macrophages by basic calcium phosphate crystals via protein kinase $C$ and MAP kinase pathways: a vicious cycle of inflammation and arterial calcification? Circ Res. 2005 Jun;96(12): 1248-56.

90 Nadra I, Boccaccini AR, Philippidis P, Whelan LC, McCarthy GM, Haskard DO, et al. Effect of particle size on hydroxyapatite crystal-induced tumor necrosis factor alpha secretion by macrophages. Atherosclerosis. 2008 Jan;196(1):98-105.

91 Jin C, Frayssinet P, Pelker R, Cwirka D, Hu $B$, Vignery A, et al. NLRP3 inflammasome plays a critical role in the pathogenesis of hydroxyapatite-associated arthropathy. Proc Natl Acad Sci U S A. 2011 Sep;108(36): 14867-72.

92 Pazár B, Ea HK, Narayan S, Kolly L, Bagnoud $\mathrm{N}$, Chobaz V, et al. Basic calcium phosphate crystals induce monocyte/macrophage IL- $1 \beta$ secretion through the NLRP3 inflammasome in vitro. J Immunol. $2011 \mathrm{Feb}$;186(4):2495502.

93 Wang Y, Liu X, Shi H, Yu Y, Yu Y, Li M, et al. NLRP3 inflammasome, an immune-inflammatory target in pathogenesis and treatment of cardiovascular diseases. Clin Transl Med. 2020 Jan;10(1):91-106.

94 Swanson KV, Deng M, Ting JP. The NLRP3 inflammasome: molecular activation and regulation to therapeutics. Nat Rev Immunol. 2019 Aug;19(8):477-89.

95 Hari A, Zhang Y, Tu Z, Detampel P, Stenner M, Ganguly A, et al. Activation of NLRP3 inflammasome by crystalline structures via cell surface contact. Sci Rep. 2014;4: 7281.

96 Bennett BJ, Scatena M, Kirk EA, Rattazzi M, Varon RM, Averill M, et al. Osteoprotegerin inactivation accelerates advanced atherosclerotic lesion progression and calcification in older ApoE-/- mice. Arterioscler Thromb Vasc Biol. 2006 Sep;26(9): 2117-24.

97 Morony S, Tintut Y, Zhang Z, Cattley RC, Van G, Dwyer D, et al. Osteoprotegerin inhibits vascular calcification without affecting atherosclerosis in $\operatorname{ldlr}(-/-)$ mice. Circulation. 2008 Jan 22;117(3):411-20.

98 Ikebuchi Y, Aoki S, Honma M, Hayashi M, Sugamori Y, Khan M, et al. Coupling of bone resorption and formation by RANKL reverse signalling. Nature. 2018 Sep;561(7722): 195-200.

99 Dautova Y, Kapustin AN, Pappert K, Epple M, Okkenhaug H, Cook SJ, et al. Calcium phosphate particles stimulate interleukin- $1 \beta$ release from human vascular smooth muscle cells: a role for spleen tyrosine kinase and exosome release. J Mol Cell Cardiol. 2018 Feb;115:82-93.

100 Grootaert MOJ, Moulis M, Roth L, Martinet W, Vindis C, Bennett MR, et al. Vascular smooth muscle cell death, autophagy and senescence in atherosclerosis. Cardiovasc Res. 2018 Mar;114(4):622-34.

101 Ewence AE, Bootman M, Roderick HL, Skepper JN, McCarthy G, Epple M, et al. Calcium phosphate crystals induce cell death in human vascular smooth muscle cells: a potential mechanism in atherosclerotic plaque destabilization. Circ Res. 2008 Aug;103(5):e28-34.

102 Clarke MC, Talib S, Figg NL, Bennett MR. Vascular smooth muscle cell apoptosis induces interleukin-1-directed inflammation: effects of hyperlipidemia-mediated inhibition of phagocytosis. Circ Res. 2010 Feb; 106(2):363-72.

103 Proudfoot D, Skepper JN, Hegyi L, Bennett MR, Shanahan CM, Weissberg PL. Apoptosis regulates human vascular calcification in vitro: evidence for initiation of vascular calcification by apoptotic bodies. Circ Res. 2000 Nov;87(11):1055-62.

104 Viegas CSB, Costa RM, Santos L, Videira PA, Silva Z, Araújo N, et al. Gla-rich protein function as an anti-inflammatory agent in monocytes/macrophages: implications for calcification-related chronic inflammatory diseases. PLoS One. 2017; 12(5):e0177829.

105 Viegas CS, Cavaco S, Neves PL, Ferreira A, João A, Williamson MK, et al. Gla-rich protein is a novel vitamin K-dependent protein present in serum that accumulates at sites of pathological calcifications. Am J Pathol. 2009 Dec;175(6):2288-98.

106 Willems BA, Furmanik M, Caron MMJ, Chatrou MLL, Kusters DHM, Welting TJM, et al. Ucma/GRP inhibits phosphate-induced vascular smooth muscle cell calcification via SMAD-dependent BMP signalling. Sci Rep. 2018 03;8(1):4961.

107 Sage AP, Lu J, Tintut Y, Demer LL. Hyperphosphatemia-induced nanocrystals upregulate the expression of bone morphogenetic protein-2 and osteopontin genes in mouse smooth muscle cells in vitro. Kidney Int. 2011 Feb;79(4):414-22.

108 Huang LH, Han J, Ouyang JM, Gui BS. Shape-dependent adhesion and endocytosis of hydroxyapatite nanoparticles on A7R5 aortic smooth muscle cells. J Cell Physiol. 2020 Jan;235(1):465-79.

109 Speer MY, McKee MD, Guldberg RE, Liaw L, Yang HY, Tung E, et al. Inactivation of the osteopontin gene enhances vascular calcification of matrix Gla protein-deficient mice: evidence for osteopontin as an inducible inhibitor of vascular calcification in vivo. J Exp Med. 2002 Oct;196(8):104755.

110 Jono S, Peinado C, Giachelli CM. Phosphorylation of osteopontin is required for inhibition of vascular smooth muscle cell calcification. J Biol Chem. 2000 Jun;275(26): 20197-203.

111 Steitz SA, Speer MY, McKee MD, Liaw L, Almeida $M$, Yang $H$, et al. Osteopontin inhibits mineral deposition and promotes regression of ectopic calcification. Am J Pathol. 2002 Dec;161(6):2035-46.

112 Yoshitake H, Rittling SR, Denhardt DT, Noda M. Osteopontin-deficient mice are resistant to ovariectomy-induced bone resorption. Proc Natl Acad Sci U S A. 1999 Jul; 96(14):8156-60.

113 Matsui Y, Rittling SR, Okamoto H, Inobe $\mathrm{M}$, Jia N, Shimizu T, et al. Osteopontin deficiency attenuates atherosclerosis in female apolipoprotein E-deficient mice. Arterioscler Thromb Vasc Biol. 2003 Jun;23(6): 1029-34.

114 Nahar-Gohad P, Gohad N, Tsai CC, Bordia $\mathrm{R}$, Vyavahare N. Rat aortic smooth muscle cells cultured on hydroxyapatite differentiate into osteoblast-like cells via BMP-2SMAD-5 pathway. Calcif Tissue Int. 2015 Apr;96(4):359-69.

115 Fakhry M, Roszkowska M, Briolay A, Bougault C, Guignandon A, Diaz-Hernandez JI, et al. TNAP stimulates vascular smooth muscle cell trans-differentiation into chondrocytes through calcium deposition and BMP-2 activation: possible implication in atherosclerotic plaque stability. Biochim Biophys Acta. 2017 Mar;1863(3):643-53.

116 Khavandgar Z, Roman H, Li J, Lee S, Vali H, Brinckmann J, et al. Elastin haploinsufficiency impedes the progression of arterial calcification in MGP-deficient mice. J Bone Miner Res. 2014 Feb;29(2):327-37.

117 Maruyama M, Rhee C, Utsunomiya T, Zhang N, Ueno M, Yao Z, et al. Modulation of the inflammatory response and bone healing. Front Endocrinol. 2020;11:386.

118 Gerstenfeld LC, Cho TJ, Kon T, Aizawa T, Cruceta J, Graves BD, et al. Impaired intramembranous bone formation during bone repair in the absence of tumor necrosis factor-alpha signaling. Cells Tissues Organs. 2001;169(3):285-94.

119 Gerstenfeld LC, Cho TJ, Kon T, Aizawa T, Tsay A, Fitch J, et al. Impaired fracture healing in the absence of TNF-alpha signaling: the role of TNF-alpha in endochondral cartilage resorption. J Bone Miner Res. 2003 Sep;18(9):1584-92.

120 Fukui N, Ikeda Y, Ohnuki T, Hikita A, Tanaka S, Yamane S, et al. Pro-inflammatory cytokine tumor necrosis factor-alpha induces bone morphogenetic protein-2 in chondrocytes via mRNA stabilization and transcriptional up-regulation. J Biol Chem. 2006 Sep; 281(37):27229-41.

121 Csiszar A, Smith KE, Koller A, Kaley G, Edwards JG, Ungvari Z. Regulation of bone morphogenetic protein-2 expression in endothelial cells: role of nuclear factor-kappaB activation by tumor necrosis factor-alpha, $\mathrm{H} 2 \mathrm{O} 2$, and high intravascular pressure. Circulation. 2005 May;111(18):2364-72.

122 Tsuji K, Bandyopadhyay A, Harfe BD, Cox K Kakar S, Gerstenfeld L, et al. BMP2 activity, although dispensable for bone formation, is required for the initiation of fracture healing. Nat Genet. 2006 Dec;38(12):1424-9. 
123 Chinetti-Gbaguidi G, Baron M, Bouhlel MA, Vanhoutte J, Copin C, Sebti Y, et al. Human atherosclerotic plaque alternative macrophages display low cholesterol handling but high phagocytosis because of distinct activities of the PPAR $\gamma$ and LXRa pathways. Circ Res. 2011 Apr 15;108(8):985-95.

124 Stöger JL, Gijbels MJ, van der Velden S, Manca M, van der Loos CM, Biessen EA, et al. Distribution of macrophage polarization markers in human atherosclerosis. Atherosclerosis. 2012 Dec;225(2):461-8.

125 de Gaetano M, Crean D, Barry M, Belton O. M1- and M2-type macrophage responses are predictive of adverse outcomes in human atherosclerosis. Front Immunol. 2016; $7: 275$.

126 Bi Y, Chen J, Hu F, Liu J, Li M, Zhao L. M2 macrophages as a potential target for antiatherosclerosis treatment. Neural Plast. 2019; 2019:6724903.

127 Shioi A, Ikari Y. Plaque calcification during atherosclerosis progression and regression. J Atheroscler Thromb. 2018 Apr 01;25(4):294303.

128 Ceneri N, Zhao L, Young BD, Healy A, Coskun S, Vasavada H, et al. Rac2 Modulates atherosclerotic calcification by regulating macrophage interleukin- $1 \beta$ production. Arterioscler Thromb Vasc Biol. 2017 Feb; 37(2):328-40

129 Ridker PM, Everett BM, Thuren T, MacFadyen JG, Chang WH, Ballantyne C, et al. Antiinflammatory therapy with canakinumab for atherosclerotic disease. N Engl J Med. 2017 Sep;377(12):111931.

130 Gomez D, Baylis RA, Durgin BG, Newman AAC, Alencar GF, Mahan S, et al. Interleukin- $1 \beta$ has atheroprotective effects in advanced atherosclerotic lesions of mice. Nat Med. 2018 Sep;24(9):1418-29. 